\title{
CASO FORTUITO O FUERZA MAYOR COMO CAUSAL DE TÉRMINO DE LA RELACIÓN LABORAL. REQUISITOS DEL CASO FORTUITO ¿SE CONFUNDEN CON LA INIMPUTABILIDAD DEL EMPLEADOR?
}

\author{
FORTUITOUS CASE OR OVERWHELMING FORCE AS \\ CAUSE FOR TERMINATION OF LABOR RELATIONSHIP. \\ REQUIREMENTS OF FORTUITOUS CASE: CAN THEY BE \\ CONFUSED WITH EMPLOYER'S INIMPUTABILITY?
}

\author{
Juan Luis Castro Jara* \\ Abogado
}

\begin{abstract}
RESUMEN: El presente trabajo plantea como problema central, si es posible determinar la procedencia del caso fortuito o fuerza mayor como causal de término de la relación laboral, centrando su análisis en la debida diligencia con la cual el empleador ha dado cumplimiento a sus obligaciones contractuales, es decir, determinando la causal tomando en cuenta sólo el elemento subjetivo. Esa parece ser la solución que inspira nuestro sistema de responsabilidad contractual civil, el cual se centra en el análisis de la culpa del deudor en el cumplimiento de sus obligaciones, y sólo una vez determinada aquélla, se traduce en la correspondiente indemnización de perjuicios, lo que debería tener plena aplicación en materia laboral. De concluirse lo anterior, se analizará cuáles son las consecuencias jurídicas que deriven, y si esta interpretación implica un menoscabo para el trabajador que ve terminado su contrato sin derecho al pago de indemnizaciones por la causal aplicada.
\end{abstract}

Palabras clave: caso fortuito - responsabilidad - despido

ABSTRACT: This paper poses the central problem if possible to determine the origin of the accident or force majeure as grounds for termination of employment, focusing his analysis on due diligence with which the employer has complied with its contractual obligations, that is ie, determining the causal considering only the subjective element. That seems to be the solution that inspires our system of civil contractual liability, which focuses on analysis of the debtor's fault in fulfilling their obligations, and only after determining it, results in the compensation of damages, the it should be fully. implemented in the workplace. To conclude the above, it will analyze what the legal consequences are derived, and if this interpretation implies a detriment to the worker sees terminated his contract without entitlement to compensation on the grounds applied.

Key words: fortuitous event - liability - dismissal

\footnotetext{
Abogado. Magíster Derecho del Trabajo y de la Seguridad Social, Universidad de Talca, Chile, Universidad de Valencia, España. Asociado Estudio Rogel \& Naudon Abogados. Contacto: jualuiscastrojara@gmail.com
} 
Juan Luis Castro Jara / Caso fortuito o fuerza mayor como causal de término de la relación laboral. Requisitos del caso fortuito ¿se confunden con la inimputabilidad del empleador?

\section{INTRODUCCIÓN}

El presente trabajo procura analizar en específico los requisitos necesarios para que se configure la causal de terminación del contrato caso fortuito o fuerza mayor, y si estos requisitos se agotan en el análisis de la inimputabilidad del empleador en el hecho que provoca el despido y en la imposibilidad de continuar cumpliendo sus obligaciones contractuales.

Por regla general, en materia civil, a fin de determinar la existencia del caso fortuito o fuerza mayor como causal de exoneración de responsabilidad en materia contractual, se realiza un análisis más bien subjetivo del comportamiento del deudor, en especial a la luz de la debida diligencia con que debió haber cumplido sus obligaciones contractuales, centrándose el análisis de este modo en la inimputabilidad del agente ¿Es posible realizar este mismo análisis para determinar la existencia de un caso fortuito o fuerza mayor como causal de término de la relación laboral? ¿Existe alguna diferencia sustancial en el concepto caso fortuito o fuerza mayor como causal de terminación del contrato de trabajo, con el concepto que sirve para exonerar de responsabilidad al deudor en materia de responsabilidad contractual civil?

La intención es revisar los requisitos necesarios para la configuración de la causal del artículo 159 número 6 del Código del Trabajo, a través del estudio de la doctrina iuslaboralista especializada, que se ha pronunciado acerca del concepto caso fortuito o fuerza mayor como causal de término del contrato de trabajo, revisando además este mismo concepto desde otras ramas del derecho, tomando en cuenta que los efectos del caso fortuito o fuerza mayor para el caso de producirse, son similares ya que en definitiva se trata de una exoneración de responsabilidad del agente.

Existen varias razones que hacen relevante esta investigación. En primer término en la doctrina nacional el caso fortuito o fuerza mayor no ha sido objeto de una atención especial por parte de los autores nacionales, encontrándose escasa bibliografía que ponga este concepto como objeto central de su análisis, lo que hace necesario un estudio pormenorizado de los elementos que lo integran, cuestión que permitirá en definitiva saber si el caso fortuito o fuerza mayor presenta o no características especiales en materia laboral, o bien, si se trata de un mismo concepto para todas las ramas del derecho donde tiene injerencia.

En segundo lugar, la necesidad de revisar la concepción tradicional de los elementos de la causal del $159 \mathrm{~N}^{\circ} 6$ del Código del Trabajo se justifica también si se considera el escenario en que se desenvuelve la relación de trabajo en la actualidad, cuando existen pocos acontecimientos que no pueden preverse o que son imposibles de resistir. En este sentido, el contrato de trabajo debe pasar a ser visto no sólo como una convención en que el trabajador debe prestar ciertos servicios y el empleador pagar una remuneración convenida, sino que también debe verse desde una perspectiva realista, como una herramienta empleada para la satisfacción de las necesidades de ambas partes contratantes, cuyos intereses son generalmente antagónicos.

Así pues, ante este nuevo escenario en que se despliega la relación de trabajo, y a la especialidad del derecho laboral que cuenta con principios que le son propios, se justifica la investigación, por cuanto a primera vista el caso fortuito o fuerza mayor como causal de término del contrato de trabajo, podría presentar características especiales que lo distinguirían del concepto establecido para el derecho común. 


\section{REQUISITOS NECESARIOS PARA LA CONFIGURACIÓN DE LA CAUSAL}

La postura doctrinal mayoritaria distingue varios requisitos copulativos bien definidos que deben concurrir para configurar la causal de terminación del contrato de trabajo caso fortuito o fuerza mayor, estableciéndose en términos generales que el hecho que provoca el despido debe ser imprevisto e irresistible para el empleador, que su ocurrencia le sea inimputable al empleador, y que exista una relación de causa a efecto entre el caso fortuito o fuerza mayor y el término de la relación laboral. Cumplido lo anterior, el Código del Trabajo dispone que la relación laboral finalice sin derecho a indemnización alguna para el trabajador.

Al momento de calificar la justificación del despido, el juez deberá determinar si los requisitos indicados se cumplen de manera copulativa, verificando a la luz de los antecedentes si concurren cada uno de ellos. De este modo, y según plantea la doctrina iuslaboralista mayoritaria, el análisis escaparía a una dimensión puramente subjetiva de la diligencia del empleador en el cumplimiento de sus obligaciones contractuales, ya que analizando sólo la imputabilidad, bastaría la mera ausencia de culpa en el hecho que provoca el despido para exonerarlo del pago de las indemnizaciones por término de contrato, sacrificándose la noción de imposibilidad en el cumplimiento de las obligaciones emanadas del contrato de trabajo en la medida en que se absorbe en la valoración del esfuerzo incluido en cada obligación.

Para los profesores Sergio Gamonal y Caterina Guidi, se configura el caso fortuito o fuerza mayor como causal de término de la relación laboral, siempre que se cumplan tres requisitos: imprevisibilidad, irresistibilidad y que el hecho no haya sido provocado por quien lo alega ${ }^{1}$. Estos autores plantean que la imprevisibilidad significa que racionalmente no existe manera de anticipar su ocurrencia. Por su parte, la irresistibilidad implica que quien lo sufre sea incapaz de evitar su ocurrencia. Agregan que el caso fortuito o fuerza mayor debe imposibilitar y excusar el cumplimiento de las obligaciones principales del contrato de trabajo de manera total y definitiva.

La profesora Karla Varas sostiene que la imprevisibilidad del hecho que provoca el término de la relación laboral, significa que éste ha sido imposible de anticipar ${ }^{2}$, postulando además que para que se configure el caso fortuito o fuerza mayor como causal de extinción del contrato, éste debe ser inimputable, irresistible, y existir una relación de causa a efecto entre el hecho y el daño. Esta autora se refiere a la irresistibilidad del hecho como el requisito más importante para la configuración del caso fortuito o fuerza mayor para efectos laborales ya que dice relación con que el hecho deba generar en el empleador una imposibilidad absoluta de cumplir con sus obligaciones.

Otro grupo de autores, al estudiar la causal de terminación del contrato del numeral 6 del artículo 159 del Código del Trabajo, no hablan del cumplimiento de requisitos copulativos para la configuración del caso fortuito o fuerza mayor, sino que simplifican su concepto al referirse derechamente a la imposibilidad total de cumplimiento del contrato para la configuración de la causal, siempre que en esta imposibilidad no tenga culpa el empleador.

Así, refiriéndose a la causal de terminación del contrato del artículo $159 \mathrm{~N}^{\circ} 6$ del Código del Trabajo, la profesora Irene Rojas señala que el fundamento del caso fortuito como causa de terminación del contrato de trabajo se basa en que este hecho imposibilita la ejecución del mismo ${ }^{3}$.

Otro autor, Manuel Vivanco Cisternas, define el caso fortuito como "Hecho no imputable a la voluntad de los obligados que impide y excusa el cumplimiento de las obligaciones", agregando

\footnotetext{
Gamonal y Guidi (2010) p. 112.

VARAS (2010a) p. 68.

ROJAS (2004) p. 243.
} 
Juan Luis Castro Jara / Caso fortuito o fuerza mayor como causal de término de la relación laboral. Requisitos del caso fortuito ¿se confunden con la inimputabilidad del empleador?

que "Fortuito es lo que ocurre o sucede inopinadamente y causalmente" (Vivanco, 1994, p. 50). En su análisis de esta causal de despido, el profesor Vivanco cita además del artículo 45 del Código Civil como fundamento legal del caso fortuito o fuerza mayor, el artículo 1547 del mismo cuerpo legal, el que en su inciso segundo, prescribe en lo pertinente que el deudor (empleador) no es responsable del caso fortuito a menos que el caso fortuito haya sobrevenido por su culpa. La prueba de la diligencia o cuidado incumbe al que ha debido emplearlo; la prueba del caso fortuito, al que lo alega. Termina el precepto del Código Civil señalando que todo lo anterior es sin perjuicio de lo que acuerden las partes o establecen las leyes especiales.

Así pues, los autores que apoyan la posición mayoritaria estableciendo los distintos requisitos copulativos que deben cumplirse para la configuración del caso fortuito, distinguen nítidamente entre el ámbito normativo de la inimputabilidad, ligado a la noción de diligencia, y el ámbito natural de la imposibilidad, determinada al margen de la diligencia.

En cuanto a la jurisprudencia nacional, la Corte Suprema, en reciente fallo de unificación de jurisprudencia, ha señalado que para que se configure la causal del artículo $159 \mathrm{~N}^{\circ} 6$ del Código del Trabajo, deben concurrir varios requisitos copulativos respecto del hecho invocado como caso fortuito o fuerza mayor para ponerle término al contrato de trabajo de su dependiente, esto es, el hecho que se imputa fortuito, debe ser inimputable, imprevisible e irresistible para el empleador, sin embargo, agrega que al análisis de los elementos del caso fortuito debe agregarse la ponderación de los factores específicos de la fisonomía propia de cada empresa para determinar la imposibilidad de continuar con la relación laboral ${ }^{4}$.

La Corte Suprema ha resuelto además respecto del caso fortuito que: "En la esencia de dicho concepto, se halla la imprevisibilidad y la irresistibilidad a que se ve expuesto el afectado por el caso fortuito o fuerza mayor. Es decir, una contingencia no posible de advertir o vislumbrar y a la que no puede oponerse el agente, que no puede ser contrariada o rechazada por éste", distinguiendo esta doctrina jurisprudencial los requisitos que deben cumplirse de manera copulativa para la configuración del caso fortuito 5 .

Existen fallos dictados por el máximo Tribunal que agregan expresamente el requisito de la inimputabilidad del deudor en el hecho que se reputa caso fortuito o fuerza mayor, señalando al efecto: “...Que dicho concepto supone la concurrencia copulativa de tres características que debe revestir el hecho que deba subsumirse en la norma pertinente, a saber, inimputabilidad, imprevisibilidad e irresistibilidad, circunstancias a las que se ve expuesto el afectado por el caso fortuito o la fuerza mayor. Ciertamente, como se dijo, constituyen requisitos copulativos..."6.

El primero de los requisitos necesarios para la configuración de la causal, exige que el hecho que provoca el despido sea inimputable al empleador, es decir, que no provenga de su culpa o dolo?.

El hecho que provoca el despido puede provenir de un hecho del mismo trabajador que se despide, e incluso configurar la causal de despido del artículo $160 \mathrm{~N}^{\circ} 7$ del Código del Trabajo cuando sucede, por ejemplo, que un trabajador no obtiene la autorización legal para realizar determinadas funciones, como podría suceder con un guardia de seguridad que vigente el contrato

\footnotetext{
4 Cea con Medina (2012).

5 Cofré con Heller (2006). Así también Smart con Inmobiliaria e Inversiones Pangal S.A (2008).

6 Ramírez con Empresa de Transportes Compañía de Seguridad de Chile Ltda. (2011).

7 Respecto de este requisito, en la doctrina comparada, algunos autores plantean que la imputabilidad o inimputabilidad del empleador en el hecho que provoca el despido puede interpretarse de dos modos: ausencia de culpa en la generación de la situación de imposibilidad de cumplimiento del contrato de trabajo y presencia de una diligencia normal en el comportamiento del deudor. Fernández (1993) p. 26.
} 
de trabajo sea condenado por crimen o simple delito, por cuanto de acuerdo a lo dispuesto la normativa vigente sobre seguridad privada en Chile, un trabajador que desempeña como guardia de seguridad no debe tener antecedentes penales ${ }^{8}$. Lo mismo ocurre en el caso de una docente que fue contratada como tal, y posteriormente queda en evidencia de que nunca obtuvo el título que exige la normativa vigente a fin de dar cumplimiento a la normativa de subvenciones estatales a la educación?.

Por otro lado, es posible identificar una segunda postura doctrinaria, tratada mayormente desde el derecho común, fundada en el sistema de responsabilidad contractual subjetiva que inspira el Código Civil, que establece a fin de calificar el caso fortuito, es fundamental el análisis de la imputabilidad del deudor en el hecho o circunstancia que hace imposible el cumplimiento del contrato, constituyendo los demás requisitos del caso fortuito sólo aspectos de la imputabilidad. Siguiendo esta doctrina, bastaría probarse la ausencia de culpa o dolo del empleador en la imposibilidad de continuar cumpliendo sus obligaciones contractuales, para configurarse la causal de terminación de contrato contemplada en el número 6 del artículo 159 del Código del Trabajo, constituyendo de este modo un concepto puramente subjetivo, tratándose en definitiva de un juicio de reproche respecto del cumplimiento de las obligaciones contractuales del empleador ${ }^{10}$.

Para el caso del terremoto ocurrido en nuestro país en el mes de febrero del año 2010, la jurisprudencia administrativa de la Dirección del Trabajo, estableció que para la aplicación estricta de la causal de terminación del contrato contenida en el artículo 159 N6 del Código del Trabajo, se requería de la reunión de los siguientes elementos: a) Que los daños ocurridos en las instalaciones de la empresa se deban causalmente a la ocurrencia del terremoto; b) que el empleador que invoque esta causal no puede haber contribuido al acaecimiento del mismo y/o a sus efectos lesivos; c) que el terremoto no se haya podido prever dentro de cálculos ordinarios o corrientes, $y$, d) Que el terremoto y sus efectos directos sean irresistibles, esto es que suponga la nula posibilidad de mantener el puesto de trabajo de los trabajadores y, por ende, de cumplir con las obligaciones contractuales de la parte empleadora ${ }^{11}$.

En primer término, se debe tener en cuenta que para proceder al deșpido de un trabajador por la causal en estudio, es necesario que el empleador cumpla con los requisitos formales establecidos para la comunicación del término de la relación laboral, exigencias que se encuentran consagradas en el artículo 162 del Código del Trabajo, y que dicen relación con la exigencia de comunicar por escrito al trabajador, señalando pormenorizadamente los hechos que fundamentan el término de la relación laboral, con copia a la inspección del trabajo, enviada dentro de los 6 días siguientes a la separación del trabajador.

En cuanto al fondo, como ya se ha referido, la mayoría de los autores distingue varios requisitos que deben concurrir copulativamente para que se configure la causal de despido del numeral 6 del artículo 159 del Código del Trabajo, por cuanto concurriendo todos los requisitos, se torna imposible el cumplimiento de las obligaciones que emanan del contrato. Estos requisitos o elementos necesarios se desprenden de la definición legal contenida en el artículo 45 del Código

\footnotetext{
* Decreto Ley 3607 de 1981 y Decreto Supremo 93 de 1985.

y González con Compagnon (2005).

10 En la doctrina comparada, también encontramos autores que distinguen las diversas teorías tendientes a definir lo que debe entenderse como caso fortuito o fuerza mayor. Así, distinguen tres fórmulas básicas que inspiran las diversas tendencias: una tesis negativa, que toma por fundamento la inexistencia de toda conducta culposa del deudor; la positiva, con base en la imprevisibilidad o inevitabilidad de los hechos; y la conciliadora que surge de la conjunción de ambos aspectos en el enjuiciamiento práctico del hecho fortuito. Fernández (1993) p. 12.

1 Dirección del Trabajo. Ord. N 1412/021, de 19 de marzo de 2010.
} 
Juan Luis Castro Jara / Caso fortuito o fuerza mayor como causal de término de la relación laboral. Requisitos del caso fortuito ¿se confunden con la inimputabilidad del empleador?

Civil, y se encuentran la inimputabilidad del agente, la imprevisibilidad e irresistibilidad del hecho que provoca el despido, agregando algunos autores la necesidad que exista un nexo causal entre el hecho que se reputa fortuito, y el despido.

Para la doctrina civilista nacional clásica, la inimputabilidad es el primero y más importante de los elementos del caso fortuito ${ }^{12} y$, como ya se ha dicho, en general consiste que el hecho que se reputa fortuito, no derive en modo alguno de la conducta culpable del deudor, que en el caso en estudio sería el empleador desde que es el deudor de la obligación de otorgar el trabajo convenido a su empleado. En materia contractual, además es necesario que el hecho que se invoca como fortuito o fuerza mayor no provenga de las personas por las cuáles el deudor es obligado a responder. Lo anterior se deriva de las normas contenidas, entre otros, los artículos 1547 inciso segundo, 1672 y 1679 del Código Civil.

Conforme lo ya referido, es posible distinguir entre una responsabilidad contractual directa y una responsabilidad contractual indirecta del empleador en la ocurrencia del hecho que se reputa como fortuito.

La responsabilidad directa descansa en la imputabilidad respecto del empleador, que deriva de la conducta culpable o falta de diligencia de éste, que excluye notoriamente el caso fortuito. Es decir, existe fuerza mayor o caso fortuito cuando el incumplimiento no es imputable a una culpa del empleador, y la culpa de éste consiste, sea en que el obstáculo es previsible y no se ha adoptado alguna medida para evitarlo, sea que al tiempo en que se presenta el obstáculo, sin que se haya debido preverse no se haga todo lo necesario para evadirlo.

En lo que se refiere a la responsabilidad contractual indirecta, es menester señalar que el problema de la inimputabilidad del caso fortuito no sólo queda resuelto con el análisis de la conducta del propio empleador, sino que también es necesario descartar la culpa de un grupo de personas que si bien, serían terceros ajenos al contrato de trabajo que termina, se encuentran ligadas de un modo u otro al empleador que debe responder por su actuar.

En cuanto a la imprevisibilidad podría decirse que es un hecho imprevisible aquello que no ha sido posible de anticipar, sin embargo, cualquier evento podría ser en alguna medida previsible, puesto que incluso los hechos imposibles han sido objeto de apreciación humana. Así, necesariamente se debe precisar en cuanto que imprevisible, es todo aquello que excede el ámbito de riesgo asignado al deudor y que naturalmente tuvo en cuenta al momento de celebrar el contrato. Comúnmente se explica la imprevisibilidad afirmando que consiste en lo que se sustrae a un cálculo de probabilidades efectuado por un hombre medio.

La previsibilidad es una calificación de carácter relativo que puede aplicarse a un suceso según lo acostumbrado o desacostumbrado de éste. La previsibilidad está siempre subordinada a la circunstancia de que se refiera a acontecimientos que racionalmente hayan podido preverse; y que depende no del hecho mismo, sino de la manera como éste se presenta; todo lo cual debe descansar sobre una valuación de la conducta del empleador, referida al grado de diligencia que éste debió emplear, desde que es él mismo quien invoca la ocurrencia de un caso fortuito o fuerza mayor para ponerle término al contrato de trabajo de sus dependientes sin contemplar el pago de indemnizaciones por término de contrato.

Los profesores Coustasse e Iturra se refieren a las características del requisito previsibilidad $^{13}$, que son las siguientes: Es relativo, ya que sólo puede valorarse cuando se la considera frente a una relación dada, al deber de previsión del obligado, a la posibilidad que éste tenía de evitar el

12 Coustasse e ItUrra (1958) p. 86.

13 Coustasse E ItUrra (1958) p. 110. 
hecho; Es concreto, es decir, para que el hecho se pueda considerar imprevisto es indispensable relacionarlo objetivamente a otras circunstancias concretas que son las que le dan tal calidad (Ej.: lugar geográfico donde ocurre el hecho, época del año, habitualidad, intensidad, etc.); y depende de la conducta del agente, ya que el hecho pasa a ser imprevisto cuando a pesar de que se han tomado las precauciones que la prudencia aconseja (o la ciencia o el arte) para evitar el riesgo, sin embargo, éste se produce porque concurrieron otros hechos o fenómenos que normalmente no concurren, $y$, por lo mismo, no pudieron precaverse.

Se ha resuelto que el término de un contrato de concesión que obliga al empresario a ponerle término a los contratos de trabajo de sus empleados, si bien consiste en un hecho irresistible para el empleador, ya que no puede evitar sus consecuencias, en ningún caso puede considerarse como imprevisible, ya que el empresario al firmar un contrato de concesión para un determinado servicio, por un tiempo previamente fijado, se encontraba en pleno conocimiento de la fecha de su término, por lo que debió prever sus consecuencias, no configurándose de este modo la causal de despido del artículo $159 \mathrm{~N}^{\circ} 6$ del Código del Trabajo ${ }^{14}$. Una situación como la descrita, más que un caso fortuito o fuerza mayor constituye una hipótesis término de la actividad productiva en que se desenvuelve la empresa que debía estar en conocimiento de la misma desde el momento en que inició dicha actividad ${ }^{15}$.

Incluso un acto de autoridad que determine la clausura de la empresa puede ser previsible, cuando en virtud de su propio actuar el empresario se ha puesto en la situación que provocó la clausura por parte de la autoridad sanitaria ${ }^{16}$. Lo mismo sucede con la declaración de quiebra de la empresa, lo que implica el cierre del negocio y el despido de sus trabajadores, no puede configurarse la causal de caso fortuito, desde que el empleador no pudo desconocer el estado de sus negocios que llevó en definitiva a la declaratoria de quiebra ${ }^{17}$.

La irresistibilidad del caso fortuito es a menudo concebida en términos absolutos, como sinónimo de imposibilidad de superar el obstáculo provocado por el caso fortuito. Así, sería irresistible aquello que es inevitable tanto para el deudor como para cualquier persona colocada en su situación.

Este concepto de irresistibilidad se refiere en forma más directa a la conducta de quien invoca el caso fortuito o fuerza mayor frente a un suceso en vías de ocurrir, inminente o ya ocurrido, $y$ consiste en defensas que se oponen al hecho imprevisto tendientes a evitar sus efectos dañosos ${ }^{18}$.

Se ha resuelto que un incendio parcial del lugar de trabajo no constituye caso fortuito para configurar la causal de terminación del contrato del número 6 del artículo 159 del Código del Trabajo, desde que sólo provoca una suspensión transitoria del servicio y el perjuicio económico provocado al empresario no fue de tal entidad que le provocara de manera permanente proseguir con su actividad habitual ${ }^{19}$. Así, tampoco constituye caso fortuito el hecho de una expropiación parcial de inmueble que sirve para el funcionamiento del local ${ }^{20}$.

\footnotetext{
14 Inostroza con Inzunza (2008). Este fallo fue confirmado por la Corte Suprema en causa ROL 264-2009 en fallo de fecha 24 de marzo de 2009, sin embargo, elimina el pago de la indemnización sustitutiva del aviso previo ya que el aviso de término de contrato se le remitió a los trabajadores con a lo menos 30 días de anticipación.

15 Mazzo con Buses Gran Santiago S.A. (2011).

16 Herrera con Sociedad Contractual Minera Tambillos (2009).

17 Olate con Empol Chile Say Empol S.A. (2006).

18 Coustasse e Iturra (1958) p. 114.

19 Herrera con Mondiglio (2006)

20 Luarte con Sociedad Comercial e Industrial Ramírez Díaz Hnos. (2006).
} 
Juan Luis Castro Jara / Caso fortuito o fuerza mayor como causal de término de la relación laboral. Requisitos del caso fortuito ¿se confunden con la inimputabilidad del empleador?

La concurrencia de todos los elementos constitutivos del caso fortuito le da vida a éste, pero para que el caso fortuito logre exonerar de responsabilidad es necesario, además, que ocasione al empleador la imposibilidad absoluta de cumplir con su obligación de otorgar el trabajo convenido. La imposibilidad consiste en que la prestación no puede ya ser efectuada por el deudor ni por otro a su nombre, como consecuencia del obstáculo insuperable que el caso fortuito ha ocasionado y frente al cual nada han valido los mayores sacrificios hechos para vencerlo ${ }^{21}$. De acuerdo a lo anterior, importante resulta distinguir entre los conceptos "imposibilidad" y "simple dificultad" ya que no es posible que el empleador se libre de sus obligaciones contractuales por el hecho de que su cumplimiento se haga más difícil $\mathbf{u}$ oneroso. La dificultad puede ser vencida mediante el empleo de un mayor esfuerzo, en tanto que la imposibilidad no es superable ni aún con el máximo sacrificio $^{22}$. Un voto de minoría de la Corte de Temuco se pronuncia respecto de este punto señalando que la imposibilidad de dar cumplimiento a las obligaciones contractuales del empleador no necesariamente debe ser absoluta para configurar la causal, y que al aplicarse la causal en estudio, el trabajador despedido se encontraría protegido por la legislación, desde que el artículo 15 de la ley 19.728 sobre seguro de cesantía, le da protección especial al empleado que ha perdido su puesto por la causal de término en estudio ${ }^{23}$.

La Corte Suprema también ha resuelto que no es necesario que la imposibilidad sea absoluta para configurar la causal del $159 \mathrm{~N}^{\circ} 6$, ya que verificado el caso que se reputa fortuito, es necesario analizar los aspectos concretos de la faena que se ve afectada, pudiendo configurarse la causal aun cuando el empresario tenga otras faenas no afectadas por el hecho, desde que la desvinculación del trabajador debe constituirse como una consecuencia lógica del caso fortuito o fuerza mayor y perseverar en la relación de trabajo a través de una faena alternativa no debe consistir en la imposición de una carga contractual más allá del tenor y sentido del contrato de trabajo, es decir "como un gravamen desprovisto de sustento fáctico y jurídico"24.

Como se ve, para la configuración de la causal del $159 \mathrm{~N}^{\circ} 6$ del Código del Trabajo, no se requiere una imposibilidad total y absoluta de continuar otorgando el trabajo convenido, sino que podría configurarse en el evento que las condiciones para mantener el vínculo laboral se vuelvan impracticables y más gravosas, máxime cuando no se contemplaron al momento de suscribir el contrato de trabajo, pudiendo la magnitud del daño causado por un siniestro poner al empleador en una situación de imposibilidad absoluta en atención a la naturaleza y características de su propio proceso productivo, revistiendo de este modo dicho siniestro la calidad de irresistible aun cuando exista una eventual posibilidad del empleador de continuar con su actividad y por ende mantener el puesto de trabajo de su dependiente.

Por otro lado, la profesora Karla Varas, también indica como requisito para la configuración de la causal de despido en estudio, que exista un vínculo causal, es decir, en cuanto a que el hecho que provoca el despido del trabajador se haya producido a consecuencia del evento invocado como caso fortuito y fuerza mayor ${ }^{25}$, sin embargo, en un voto de minoría de la Corte Suprema se determinó que se para que se configure la eximente de responsabilidad contractual de caso

\footnotetext{
$21 \quad$ Coustasse e Iturra (1958) p. 116.

22 Coustasse e Iturra (1958) p. 116.

23 Voto de minoría redactado por el abogado integrante de la Iltma. Corte de Apelaciones de Temuco don Eduardo Alamos Vera en Alvarado con Industrial Centec S.A. (2008).

24 Alvarado y otros con Industrial Centec S.A. (2009).

25 VARAS (2010a) p. 72.
} 
fortuito o fuerza mayor, únicamente sería procedente la ausencia total de voluntad del deudor en el hecho que configura la causal, independiente de las causas que la hayan motivado ${ }^{26}$.

\section{INIMPUTABILIDAD DEL EMPLEADOR Y SUS EFECTOS}

En términos generales, la doctrina nacional civilista, concibe el caso fortuito en un sentido estrictamente subjetivo, como negación de la culpa (en tanto sus requisitos se traducen en ausencia de ésta) y explica la exoneración de la responsabilidad como consecuencia de la extinción de la obligación generada por la imposibilidad de cumplimiento a que da lugar el caso fortuito.

Dicho lo anterior, y tomando en cuenta que en Chile existe un sistema de responsabilidad contractual subjetiva, la ausencia de culpa o dolo del empleador en la imposibilidad de continuar cumpliendo sus obligaciones contractuales, bastaría para configurar la causal de término de contrato establecida en el número 6 del artículo 159 del Código del Trabajo.

El deber de ocupación efectiva y adecuada emana del carácter personal del contrato de trabajo, en virtud del cual el empleador debe cumplir ciertas obligaciones dispuestas en la ley para proteger a su empleado ${ }^{27}$. En virtud de este deber, el empleador se encuentra obligado a dar el puesto de trabajo, y es precisamente esta la obligación que se hace imposible de cumplir como consecuencia de un caso fortuito o fuerza mayor.

De este modo, siendo el empresario deudor de la obligación de dar el trabajo convenido a su empleado, la causal de despido del artículo $159 \mathrm{~N}^{\circ} 6$ del Código del Trabajo, no tendría diferencia alguna con la norma de exención de responsabilidad establecida en el artículo 1547 del Código Civil, debiendo el patrón, en consecuencia, responder hasta de la culpa leve en el cumplimiento de sus obligaciones contractuales.

Al momento de la celebración del contrato de trabajo, nace el deber de ocupación efectiva y adecuada, por lo que el empleador, siendo el beneficiario del trabajo, debe prever las condiciones necesarias para mantener el puesto de su dependiente, a lo menos durante la duración del contrato, por lo que la previsibilidad o imprevisibilidad de determinado hecho que haga imposible seguir confiriendo el trabajo, debe analizarse desde la diligencia con la cual el empresario ha cumplido sus obligaciones, es decir, un análisis respecto de la culpa, lo que guarda íntima relación con la imputabilidad del empleador. Lo mismo ocurre con la irresistibilidad del caso fortuito o fuerza mayor, desde que en el mundo contemporáneo existen pocos hechos que sean totalmente irresistibles ya que a través de la contratación de seguros, la inversión en tecnología o el pago de indemnizaciones por parte de la autoridad pública (como podría ocurrir en el caso de una expropiación), la empresa podría fácilmente continuar con su actividad pese haber sido víctima de un desastre natural, un hecho delictual o terrorista, un acto de autoridad o cualquier otro acontecimiento que pudiera calificarse de caso fortuito o fuerza mayor, lo que necesariamente implica que la irresistibilidad del hecho que hace imposible el cumplimiento contractual debe analizarse respecto de la diligencia con que el empresario ha ejecutado las obligaciones que le son propias, es decir, un análisis desde la culpa.

Conforme a los fallos citados en el acápite anterior, tradicionalmente la jurisprudencia ha establecido la existencia de a lo menos dos requisitos o elementos necesarios para la configuración

\footnotetext{
26 Morales con Harbison-Walker Refractories S.A. (2009). En este caso, la discusión se centraba en la configuración del caso fortuito o fuerza mayor como eximente de la obligación del trabajador de asistir prestar funciones; sin embargo, este tema no es pacífico desde que existen fallos en sentido contrario, como Silva con Fluor Chile S.A. (2010).

27 Thayer y Novoa (1998) p. 550.
} 
Juan Luis Castro Jara / Caso fortuito o fuerza mayor como causal de término de la relación laboral. Requisitos del caso fortuito ¿se confunden con la inimputabilidad del empleador?

de un caso fortuito o fuerza mayor en materia de responsabilidad contractual: la imprevisibilidad y la irresistibilidad del hecho, sin embargo, el análisis que se hace de los requisitos anotados es siempre desde la diligencia en virtud de la cual el deudor ha dado cumplimiento a sus obligaciones contractuales. Así, no será imprevisible una declaración de quiebra desde que el empresario debió conocer el estado de calamidad general de sus negocios que la precedió, y por ende debió prever las consecuencias. El hecho será irresistible, si la obligación se hace imposible de cumplir para cualquier persona puesta en el mismo lugar que el deudor, es decir, tomando en consideración sus propias facultades. Conforme a ello, pareciera ser que el análisis que realizan los tribunales, en especial la Corte Suprema, se centra en un análisis de la culpa del empresario, por lo que en definitiva lo más importante al analizar si se configura o no la causal de término de contrato caso fortuito o fuerza mayor es precisamente la imputabilidad o inimputabilidad del empleador respecto del hecho que se reputa fortuito y que hace imposible seguir cumpliendo con su obligación de otorgar el trabajo convenido, no existiendo diferencias sustanciales en cuanto a determinar la causal de término de contrato del numeral 6 del artículo 159 del Código del Trabajo, con el concepto de caso fortuito o fuerza mayor que sirve como eximente de responsabilidad del deudor en materia de responsabilidad contractual.

Respecto del tema en estudio, el máximo tribunal ha establecido la siguiente doctrina respecto de la inimputabilidad necesaria para la configuración del caso fortuito como causal de término de la relación laboral: “... se trata de una contingencia ajena a la voluntad del afectado..." 28 .

Los profesores Coustasse e Iturra señalan que los requisitos del caso fortuito o fuerza mayor distintos de la inimputabilidad (imprevisibilidad e irresistibilidad), no son, en su esencia, algo distinto de la inimputabilidad, sino que forman parte integrante de ella ${ }^{29}$. De este modo, para que el hecho sea inimputable, preciso es que sea imprevisible e imposible de resistir; de lo contrario, mal podríamos decir que el suceso sea totalmente ajeno a la conducta culpable del agente. Por otra parte, estos elementos también resultan de la comparación que se haga respecto a los distintos grados de diligencia que el empleador puede haber empleado frente al acontecimiento.

Desde el ámbito del Derecho Penal se estudia el caso fortuito como causal excluyente de culpabilidad ${ }^{30}$, consagrándose en el numeral $8^{\circ}$ del artículo 10 del Código Penal, que dispone: "Están exentos de responsabilidad criminal:... $8^{\circ} \mathrm{El}$ que con ocasión de ejecutar un acto licito, con la debida diligencia, causa un mal por mero accidente", cobrando de este modo relevancia para determinar la existencia de la eximente el análisis de la diligencia de quien la invoca. El Código Penal establece en su artículo $1^{\circ}$ : "Es delito toda acción u omisión voluntaria penada por la ley". En el caso fortuito, el legislador penal ha constatado la ausencia del elemento intencional del delito y le ha dado consagración específica.

Para la doctrina penal, la acción del agente supone una separación intelectual en dos campos, objetivo y subjetivo. El primero es la actuación u omisión del agente, que se manifiesta en un resultado material, y el elemento subjetivo es la disposición psicológica que produce aquel determinado efecto exterior ${ }^{31}$.

La causal excluyente de culpabilidad del número 8 del artículo 10 del Código Penal establece tres requisitos para su configuración: a) Acto lícito; b) Que el acto se ejecute con la debida diligencia, y c) Que el mal causado ocurra por mero accidente.

\footnotetext{
28 Ramírez con Empresa de Transportes Compañía de Seguridad de Chile Ltda. (2011).

29 Coustasse e ITURra (1958) p. 109.

30 Rodríguez (1964) p. 12.

31 Rodríguez (1964) p. 14.
} 
La debida diligencia, presupuesto de la inimputabilidad, está integrada por el conjunto de precauciones racionales que toman los hombres prudentes en su conducta; exige la previsión y el cuidado necesarios para que el acto a realizar no origine consecuencias dañosas ${ }^{32}$. El mero accidente consiste en el hecho material susceptible de apreciación objetiva, y su causa debe escapar tanto al querer como a la previsión del agente; en cuanto a este aspecto de la previsibilidad, la doctrina penal estima que es preciso tomar en cuenta el estado de cultura, la experiencia del individuo $y$ todas las circunstancias de carácter persona ${ }^{33}$. En cuanto al último de los requisitos, nuevamente es necesario analizar la culpabilidad del agente, ya que éste es el elemento típicamente subjetivo del delito, que no puede subordinarse al texto de una disposición que actúa en previsión de ciertos hechos potencialmente de peligro.

Imputar, según el Diccionario de la Real Academia de la Lengua, es atribuir a otro una culpa, delito o acción. De lo anterior se desprende que la imputación en el plano jurídico implica atribuir a una persona como suyo determinado comportamiento que le acarreará consecuencias jurídicas. En términos lingüísticos, la imputabilidad se predica como una calidad de quien es imputable, y el imputable, aquel a quien se le puede imputar algo ${ }^{34}$.

El concepto de imputabilidad presupone para la doctrina penal clásica, inteligencia y libertad moral de la persona que actúa. Por su parte, el concepto de inimputabilidad supone en la persona de quien se predica incapacidad para conocer y comprender la ilicitud del acto, o para determinarse con esa comprensión ${ }^{35}$.

Como se ve, tanto para la doctrina especializada en materia penal, como también para la doctrina civilista, el estudio de la imputabilidad o inimputabilidad implica el análisis de la voluntad del agente en relación a determinado acto que le pudiera acarrear consecuencias jurídicas. Sólo una vez verificada la imputabilidad del agente se producirán las secuelas del hecho.

A partir de lo dispuesto en los artículos 44 y 1547 del Código Civil, la presencia de la culpa del agente, o de la falta de la debida diligencia es insoslayable para la noción de caso fortuito, lo que indica que en definitiva la imputabilidad sería el principal elemento para la configuración de la causal de término de contrato en estudio. En este sentido, si se determina que los elementos que conforman el supuesto de hecho del caso fortuito se reducen únicamente a la ausencia de culpa, podría darse lugar a un concepto estrictamente subjetivo de caso fortuito.

Tradicionalmente en Chile, tanto para la doctrina como también para la jurisprudencia, todas las consecuencias del incumplimiento contractual se afirman sobre la base de la culpa o la falta de la debida diligencia, de modo que ellas se traducirán en un reproche al deudor por haber faltado a la diligencia debida en el cumplimiento de su obligación. En el fondo, esto se vincula con la tesis que ha imperado en la doctrina chilena en lo que se refiere al incumplimiento contractual mismo, el que ha sido entendido como una acción antijurídica, constitutiva de una infracción culpable del deudor de sus obligaciones propias, envolviendo una valoración subjetiva de la conducta. Esto justifica que las consecuencias del incumplimiento, así como su exclusión se conciban aparejadas a la existencia o ausencia de un criterio de imputación del incumplimiento al deudor: la culpa. El incumplimiento se presume culpable y las consecuencias del mișmo se consideran sanciones impuestas al deudor que ha incurrido en la conducta rechazada por el ordenamiento jurídico ${ }^{36}$.

\footnotetext{
32 RoDRíGUEz (1964) p. 14.

33 Rodríguez (1964) p. 16.

34 ReYes (1997) p. 36.

35 Reyes (1997) p. 41.

36 FUEYo (2004) p. 256.
} 
Juan Luis Castro Jara / Caso fortuito o fuerza mayor como causal de término de la relación laboral. Requisitos del caso fortuito jse confunden con la inimputabilidad del empleador?

Sin perjuicio de todo lo dicho a este respecto, frente a esta visión clásica del caso fortuito, han surgido más recientemente opiniones doctrinales que tratan de configurar el caso fortuito de una forma diversa. Se trata de planteamientos que, sostienen la necesidad de objetivar la noción de caso fortuito o fuerza mayor, desvinculándola de la noción de culpa, lo que se manifiesta fundamentalmente en la forma de explicar la exigencia de la exterioridad del hecho ${ }^{37}$.

La exterioridad del hecho se trata de un elemento que no está expresamente previsto en el Código Civil, no obstante lo cual es reconocido por parte de la doctrina y admitido por los Tribunales $^{38}$. Claramente la exterioridad del hecho se asimila al concepto inimputabilidad del agente en la ocurrencia del hecho que se reputa como fortuito. En relación a esto, parte de la doctrina plantea que es posible reformular la concepción del elemento inimputabilidad a través de un nuevo enfoque del análisis de la exterioridad del hecho, permitiendo con ello una cierta objetivación del concepto de caso fortuito, demostrando que éste, si bien está estrechamente vinculado con el deber de diligencia (en razón de la imprevisibilidad e irresistibilidad que lo caracterizan), no sería simplemente la negación de culpa, de modo que no se trataría de una noción estrictamente subjetiva ${ }^{39}$. Estos autores explican la exterioridad sin recurrir a la noción de culpa, llevando su fundamento y contenido al plano de la causalidad. De acuerdo a ello, la exterioridad consistiría en la ausencia de vínculo causal entre la conducta del deudor y el hecho que ocasione el incumplimiento contractual.

Lo anterior da pie para estudiar el sistema de responsabilidad contractual existente en el país y su relación con la causal de término de contrato de trabajo caso fortuito o fuerza mayor, lo que se hará en el acápite siguiente.

\section{RESPONSABILIDAD CONTRACTUAL Y CASO FORTUITO O FUERZA MAYOR}

Según lo expuesto en este trabajo, la existencia o no del caso fortuito que provoca la terminación del contrato de trabajo descansa en definitiva sobre la valuación de la conducta del empleador frente al suceso dañoso que provoca el despido.

A fin de configurarse el caso fortuito o fuerza mayor, es menester determinar si el empleador, quien es el deudor del deber de ocupación efectiva y adecuada, empleó o no la debida diligencia y cuidado en el cumplimiento de sus obligaciones contractuales, en la previsión y en la resistencia frente a dicho evento. La prueba del caso fortuito debe descansar sobre la prueba de la diligencia y cuidado del empresario en el cumplimiento de sus obligaciones, toda vez que de no acreditarse lo anterior, la empresa deberá pagar al trabajador las indemnizaciones correspondientes al término del contrato, recargada la indemnización por años de servicio en un $50 \%$, según lo dispone el artículo 168 del Código del Trabajo. Esta interpretación se encuentra en perfecta armonía con el sistema de responsabilidad contractual vigente en el ordenamiento jurídico nacional.

La responsabilidad contractual se la define corrientemente como aquella clase de responsabilidad que proviene del incumplimiento imputable de un contrato y se traduce en la correspondiente indemnización de perjuicios, de conformidad con el artículo 1556 del Código Civil ${ }^{40}$.

\footnotetext{
$37 \quad$ BRANTt (2010) p. 22.

38 Inmobiliaria Italia con Jar Ingeniería y Servicios (2006); Pozo con Transportes Servidiario S.A. (2006); Soc. Aussicht Chile Ltda. con Municipalidad San Francisco de Mostazal (2006).

39 BrantT (2010) p. 54.

40 Coustasse e Iturra (1958) p. 16.
} 
El artículo 1556 citado, determina que deben ser indemnizados los perjuicios que se causen al acreedor por no haberse cumplido la obligación, por haberse cumplido imperfectamente o por haberse retardado su cumplimiento y que provengan de culpa o dolo del deudor. En cuanto a la institución en estudio, cabe señalar que producido el caso fortuito, el empleador deja de cumplir con su obligación derivada del deber de ocupación efectiva y adecuada, esto es, otorgar el trabajo convenido, por lo que si el juez llamado a pronunciarse sobre la justificación del despido determina que no se configura el caso fortuito o fuerza mayor invocado, el empresario deberá indemnizar al trabajador, pagándole al trabajador una indemnización tarifada como consecuencia de su incumplimiento contractual ${ }^{41}$.

De este modo, la causal de término de contrato en estudio debe analizarse desde la perspectiva de la responsabilidad contractual, ya que existiendo un contrato de trabajo que debe terminar, se verifica el elemento diferenciador con la responsabilidad extracontractual, esto es, un vínculo jurídico anterior al hecho dañoso que acarrea la responsabilidad. Conforme a este criterio, el pago de las indemnizaciones por término de contrato que deberá pagar el empleador a su dependiente para el caso de una aplicación injustificada de la causal de término del $159 \mathrm{~N}^{\circ} 6$ del Código del Trabajo, constituye una sanción que la ley le impone por no cumplir con su obligación de otorgar el trabajo convenido. De esta manera la responsabilidad viene a ser un efecto derivado de la fuerza obligatoria del contrato.

En la legislación nacional existe una clara diferencia entre la responsabilidad contractual y la extracontractual desde que se regulan en partes distintas del Código Civil, ya que la contractual se regula en el título denominado "Del efecto de las obligaciones", mientras que, por otra parte reconoce expresamente que los delitos y cuasi-delitos son fuente de las obligaciones, en el artículo 1437. Lo anterior se refuerza por la norma del artículo 2284 del Código Civil que dispone: "Las obligaciones que se contraen sin convención nacen, o de la ley o del hecho voluntario de las partes".

Otro argumento que evidencia la diferenciación existente entre la responsabilidad contractual y extracontractual lo proporciona el efecto novatorio que produce el incumplimiento contractual, el que se consagra en el artículo 1670 del Código Civil que dispone que la pérdida de la cosa debida extingue la obligación, sin embargo, si la pérdida es imputable al deudor, la obligación subsiste, pero cambia de objeto, ya que el deudor es obligado a pagar el valor de la cosa y a indemnizar los perjuicios al acreedor.

La importancia del efecto novatorio consiste en que el deudor culpable queda responsable de los perjuicios que se previeron o pudieron preverse al tiempo del contrato y no de los que se previeron o pudieron preverse al tiempo del incumplimiento (artículo 1558 del Código Civil) ${ }^{42}$.

Respecto a lo señalado en el párrafo anterior importante resulta recordar la opinión de don René Abeliuk en cuanto a que lo imprevisto del caso fortuito se configura cuando ocurre un hecho que las partes no han podido prever al momento de celebrar el acto o contrato ${ }^{43}$.

Como ya se dijo, del incumplimiento contractual deriva la obligación de la parte incumplidora de indemnizar los perjuicios a la parte diligente. A fin de que sea procedente la indemnización de perjuicios, no basta el simple incumplimiento contractual, sino que es necesario que se verifiquen ciertos requisitos.

\footnotetext{
41 Se ha resuelto en algunos fallos que el derecho laboral establece un sistema de indemnización tarifada por término de contrato, sin embargo, a través de las acciones establecidas en la legislación común, es posible para el trabajador reclamar otro tipo de indemnizaciones, como el daño moral derivado de un despido injustificado. Así por ejemplo, Suazo con CODELCO Chile, División CODELCO Norte (2011).

12 Coustasse e Iturra (1958) p. 18.

43 Abeliuk (2008) p. 135.
} 
Juan Luis Castro Jara / Caso fortuito o fuerza mayor como causal de término de la relación laboral. Requisitos del caso fortuito ¿se confunden con la inimputabilidad del empleador?

En primer término, el artículo 1557 del Código Civil dispone que para que el deudor deba la indemnización de perjuicios, es menester que sea previamente constituido en mora; a menos que se trate de una obligación de no hacer, en cuyo caso aquélla se debe desde el momento de la contravención. Analizada esta norma a la luz del tema en estudio, es evidente que al invocar la causal del término de contrato establecida en el número 6 del artículo 159 del Código del Trabajo, el empleador incurriría en mora de su obligación de otorgar el trabajo convenido, derivada del deber de ocupación efectiva y adecuada, cumpliéndose de este modo el primero de los requisitos para la indemnización de perjuicios derivada de la responsabilidad contractual.

El segundo de los requisitos necesarios para la procedencia de la indemnización de perjuicios derivada de la responsabilidad contractual, dice relación con la capacidad del deudor. Por regla general, toda persona es legalmente capaz, excepto aquéllas que la ley declara incapaces (artículo 1446 del Código Civil). En este sentido, al momento de determinar la responsabilidad contractual es necesario verificar que el deudor no se encuentre en alguna de las hipótesis de incapacidad establecidas en el artículo 1447 del Código Civil. En materia laboral, el análisis de este requisito cobra relevancia sólo para el caso que el empleador sea una persona natural.

Como tercer requisito establecido por el Código Civil para la determinación de la responsabilidad contractual, dice relación con la culpa del deudor en el incumplimiento de sus obligaciones contractuales. Los artículos 44 y 1547 inciso primero, ambos del Código Civil, consagran la doctrina clásica de la clasificación tripartita de la culpa, distinguiéndose entre culpa grave o lata, culpa leve y culpa levísima, y el deudor responde de una u otra, según sea el beneficio o utilidad de quien ceda el contrato, conforme a la naturaleza de este. Constituyendo el contrato de trabajo un contrato sinalagmático, las partes responden hasta de la culpa leve.

El último de los requisitos establecidos para la procedencia dice relación con el peso de la prueba en materia de responsabilidad, toda vez que para que sea procedente la indemnización de perjuicios es necesario que se acrediten los elementos constitutivos de la responsabilidad ante el Tribunal competente. Sobre este punto importante resulta señalar que en materia de responsabilidad contractual, a diferencia de lo que ocurre en la responsabilidad derivada por un delito o cuasidelito, la culpa del deudor se presume, quedando exonerado de esta prueba la víctima del daño, operando a su favor una inversión del onus probandi. Con respecto a esto, los profesores Coustasse e Iturra estiman que en materia de responsabilidad contractual no es exacto que la culpa se presuma, lo que ocurre es que ella queda establecida desde que el acreedor prueba la obligación, mientras que el deudor no pruebe su irresponsabilidad, porque sólo el incumplimiento por parte de éste acredita su propia culpa ${ }^{44}$.

Más que una presunción de culpa, opera una inversión del peso de la prueba en favor del acreedor. Al respecto, resulta necesario analizar la norma del inciso tercero del artículo 1547 del Código Civil que dispone: "la prueba de la diligencia y cuidado incumbe al que ha debido emplearlo", así como también lo dispuesto en el inciso primero del artículo 1698 del mismo cuerpo legal que expresa por su parte: “incumbe probar las obligaciones o su extinción al que alega aquéllas o esta”.

En materia procesal laboral, al parecer las normas transcritas del Código Civil no serían necesarias para el caso de un juicio en que se reclame la aplicación injustificada de la causal de término de contrato caso fortuito o fuerza mayor, desde que existe la disposición contenida en el artículo $454 \mathrm{~N}^{\circ} 1$ del Código del Trabajo que dispone en lo pertinente: “...en los juicios sobre despido corresponderá en primer lugar al demandado la rendición de la prueba, debiendo acreditar la veracidad de los hechos imputados en las comunicaciones a que se refieren los incisos primer y cuarto

44 Coustasse e ItURRA (1958) p. 26. 
del artículo 162, sin que pueda alegar en el juicio hechos distintos como justificativos del despido", sin embargo, la aplicación de la norma trascrita podría discutirse desde que para alguna parte de la doctrina, la causal del $159 \mathrm{~N}^{\circ} 6$ del Código del Trabajo no constituiría un despido propiamente tal, sino que se trataría de un caso de extinción del contrato de trabajo ${ }^{45}$. Esto fundado en que el despido se produce por una ruptura de la relación laboral iniciada o motivada por una decisión del empleador, en circunstancias de que el artículo 159 del Código del Trabajo, donde se contempla la causal en estudio, señala los casos por los cuáles se extingue el contrato de trabajo, independientemente del comportamiento observado por las partes.

La palabra "caso" en su sentido forense o legal, significa, según el diccionario de la Real Academia de la Lengua Española, un "hecho no imputable a la voluntad del obligado que impide y excusa el cumplimiento de sus obligaciones ${ }^{246}$. Como en el contrato de trabajo hay obligaciones permanentes y recíprocas, tanto del empleador como del trabajador, ello significa que por las causales contempladas en el artículo 159 citado, la ruptura de la relación de trabajo es normal, pues proviene de hechos no imputables a la conducta unilateral de las partes.

Sin perjuicio de ser discutible si la aplicación de la causal del $159 \mathrm{~N}^{\circ} 6$ del Código del Trabajo constituye un despido o no, y en consecuencia poder discutirse la aplicación de la norma del número 1 del artículo 454 del Código del Trabajo en un juicio laboral en que se reclame la aplicación injustificada de la causal, de acuerdo a las normas contenidas en el derecho común, igualmente le corresponderá al empleador acreditar la existencia del caso fortuito o fuerza mayor que invoca para poner término al contrato de su dependiente.

Ahora bien, ¿cuál es el fundamento de la responsabilidad?, lo anterior es importante por cuánto se debe precisar en virtud de qué razón una persona queda obligada a reparar el daño sufrido por otra. Existen principalmente dos sistemas que dan respuesta a esta interrogante: el sistema de la responsabilidad subjetiva, que fundamenta la responsabilidad en la culpa del agente, y el sistema de la responsabilidad objetiva o teoría del riesgo creado, que prescinde del elemento culpabilidad, atendiendo sólo a la existencia del daño y a la persona de su autor material.

En Chile, existe amplio consenso en la doctrina y jurisprudencia, de que a la ley la inspira el sistema de responsabilidad subjetiva, en virtud del cual es la culpabilidad del autor del daño o de las personas por las cuáles éste responde, el requisito necesario de existencia de responsabilidad. Esto significa que para que exista responsabilidad, es menester no sólo la ocurrencia del daño y la relación de causalidad entre éste y su autor, sino además se exige la existencia de un juicio de reproche respecto de la conducta del agente, es decir, que el hecho dañoso provenga del dolo o culpa del agente, que le sea imputable. Este criterio de imputabilidad hace indispensable un examen del comportamiento del deudor, lo que origina el nombre de subjetiva.

En el campo de la responsabilidad extracontractual, el carácter subjetivo de la responsabilidad alcanza su verdadera importancia ya que en materia contractual opera una inversión del peso de la prueba en favor del acreedor, o sea, la culpa queda establecida por sí misma, desde que el acreedor prueba su obligación, mientras el deudor no pruebe su irresponsabilidad porque el sólo incumplimiento de éste acredita su propia culpa. A contrario sensu, en materia extracontractual, es el demandante, presunto acreedor, sobre quien va a recaer el peso de la prueba de la culpa en que ha incurrido su demandado, y esta prueba debe dejar debe dejar establecido que los hechos dañosos tienen su origen en la falta de diligencia o cuidado de éste.

45 Vivanco (1994) p. 29.

46 Real Academia Española (2015). 
Juan Luis Castro Jara / Caso fortuito o fuerza mayor como causal de término de la relación laboral. Requisitos del caso fortuito ¿se confunden con la inimputabilidad del empleador?

En cuanto a la responsabilidad contractual, de acuerdo a la norma del artículo 1547 inciso $1^{\circ}$ del Código Civil, queda claro que su fundamento es la culpabilidad del deudor en el incumplimiento de sus obligaciones contractuales, en cuanto esta norma dispone: "el deudor no es responsable sino de la culpa lata en los contratos que por su naturaleza sólo son útiles al acreedor; es responsable de la leve en los contratos que se hacen para el beneficio recíproco de las partes; $y$ de la levísima, en los contratos en que el deudor es el único que reporta beneficios". Por su parte, el artículo 44 del mismo Código define las diferentes clases de culpa en que puede incurrir el deudor, por lo cual aquélla disposición debe entenderse en relación coń la recién mencionada.

Las críticas al sistema de responsabilidad subjetiva derivan de las dificultades que presenta la prueba de uno de sus elementos más importantes: el concepto de culpa ${ }^{47}$. No obstante esto, en materia de responsabilidad contractual existe un paliativo a esta crítica desde que es el deudor quien, para exonerarse de la obligación de indemnizar los perjuicios, deberá rendir prueba conducente a acreditar que actuó con la debida diligencia y cuidado en el cumplimiento de sus obligaciones.

Cabe ahora analizar los elementos de la responsabilidad culpa y dolo, los que dicen relación directa con el tema en estudio. El Código Civil ha definido la culpa en su artículo 44 ya citado, y consiste necesariamente en un error de conducta, que tiene su origen en el hecho de que el autor del daño no actuó con la debida diligencia y cuidado.

Con respecto al problema de determinar el criterio comparativo con que se va a juzgar el error de conducta en que consiste la culpa, existen dos puntos de vista: el de la apreciación de la culpa in concreto y el de su apreciación in abstracto.

La apreciación de la culpa in concreto consiste en considerar solamente a la persona del autor del daño su propio estado de ánimo, sus condiciones personales, para averiguar si habría podido o no actuar en mejor forma de la que actuó. Este criterio se critica aduciéndose que él vendría a convertir la culpa en una noción de carácter puramente subjetivo.

La apreciación de la culpa in abstracto consiste en comparar la conducta del agente con la de un hombre prudente colocado en la misma situación, pero como este tipo de hombre varía con el tiempo, el lugar y el medio social a que pertenece, el juez deberá tomar en cuenta todas estas circunstancias externas en contraposición con las internas, que dicen relación con las condiciones personales del agente, como su sexo, edad, carácter, estado de ánimo, etc., y de las cuáles hay que prescindir.

El criterio seguido por el legislador nacional es el de la apreciación de la culpa in abstracto ${ }^{48}$ en cuanto la alusión del artículo 44 del Código Civil hace al cuidado o diligencia de un tipo de hombre ideal que él imagina, al definir la culpa, la referencia al buen padre de familia, que hace el inciso $4^{\circ}$ del mismo artículo y la que, en idéntico sentido, hace el artículo 2323 , lo que lleva forzosamente a la conclusión señalada.

En cuanto al dolo, existen tres órdenes de materia en que puede incidir: 1.- Como vicio del consentimiento, cuando incide en la celebración de un acto jurídico (1451 del Código Civil); 2.Como circunstancia agravante de la responsabilidad del deudor, tratándose de la ejecución de las obligaciones (1558 del Código Civil); y 3.- Como elemento de los delitos civiles (artículos 2284, 2314 y 2417 del Código Civil).

$47 \quad$ Vivanco (1994) p. 29.

48 Coustasse e Iturra (1958) p. 43. 
Sin perjuicio de lo recién expuesto, cualquiera que sea el caso en que el dolo incida, la ley ha dado una sola definición de él, la que se encuentra en el inciso final del artículo 44 del Código Civil que dice: "el dolo consiste en la intención positiva de inferir injuria a la persona o propiedad de otro".

Del concepto de dolo anteriormente dado, se infiere que uno de sus elementos fundamentales es la intención, que esté determinada a causar daño a otro, sea en sus bienes o en su persona. Se entiende por intención aquel esfuerzo de la voluntad dirigido a la consecución de una finalidad precisa y concreta.

Como se ve, la presencia de la culpa o falta de la diligencia debida en sede de atribución de responsabilidad es insoslayable, a partir de lo previsto en los artículos 1547 y 44 del Código Civil.

\section{RESPONSABILIDAD DEL EMPRESARIO POR EL ACTUAR DE TERCEROS}

En el acápite anterior se analizó la responsabilidad del deudor directo de la obligación de otorgar el trabajo convenido ante la ocurrencia de un caso fortuito o fuerza mayor, sin embargo, la ocurrencia de este evento puede provenir como consecuencia del actuar de terceros, e igualmente el empresario deberá responder por los perjuicios causados, es decir, podría ocurrir que determinado hecho que hace imposible continuar con la relación laboral, provenga del dolo o culpa de un tercero ajeno a la relación contractual existente entre empleador y trabajador, e igualmente el empresario ser responsable de la indemnización de perjuicios traducida en el pago de las indemnizaciones legales como consecuencia del término de la relación de trabajo.

Es evidente que el engranaje que implica una empresa y su organización da lugar al surgimiento de diversos eventos susceptibles de afectar la ejecución de un contrato de trabajo, ya que el negocio del empresario implicará para éste último el despliegue de un grupo más o menos complejo de medios que debe conocer y manejar pues forman parte de su giro o actividad habitual.

El contenido de este riesgo típico puede ser dividido en dos grandes categorías. Por una parte se encuentran los riesgos vinculados con los sujetos que participan de la actividad de la empresa, es decir, las personas cuya intervención es necesaria para el desarrollo de la misma, y por otra parte, se ubican los riesgos vinculados con los medios no personales empleados en el negocio, o sea, los correspondientes a todos los recursos materiales e inmateriales utilizados por el empresario en la organización, preparación y ejecución de sus prestaciones.

En cuanto a la primera categoría cabe ubicar, en general, el riesgo de incumplimiento derivado de la conducta de todas aquéllas personas distintas del empresario y que intervienen ya sea en la planificación, preparación o ejecución del negocio. En este sentido, don Luis Claro Solar afirma que "la responsabilidad del deudor por los actos u omisiones de sus auxiliares es una imperiosa necesidad económica", impuesta por el desarrollo de la industria, y que "en la organización económica contemporánea una multitud de individuos coopera de diversas maneras a la ejecución de una obra ${ }^{49}$.

El funcionamiento de una empresa supone, por su propia definición, la participación de un cierto número de personas que conforman el factor trabajo dentro de dicha organización, desarrollando al interior de las mismas funciones que inciden directa o indirectamente en la ejecución del negocio o la prestación del servicio. Al mismo tiempo, los avances tecnológicos, así como también las exigencias económicas, han favorecido el fenómeno de la especialización, de modo tal que muy habitualmente el empresario deberá recurrir a terceros que de diversa forma participan en la

$19 \quad$ Claro (1978) p. 543. 
Juan Luis Castro Jara / Caso fortuito o fuerza mayor como causal de término de la relación laboral. Requisitos del caso fortuito ¿se confunden con la inimputabilidad del empleador?

ejecución de sus prestaciones o constituyen el presupuesto del cumplimiento de las mismas. Así ocurre con los contratistas o subcontratistas que en cierta medida sustituyen al empleador en la ejecución de su negocio, y también con los proveedores, quienes si bien no participan directamente en el negocio del empresario, influyen igualmente en él con los suministros de que se trate. De ahí que exista una pluralidad de sujetos cuya actividad, junto con ser necesaria para el desarrollo de la empresa, constituye un riesgo de la misma.

Dentro de esta categoría de riesgos, en primer lugar habría que ubicar la actividad de los denominados auxiliares del deudor. En una acepción amplia, esta expresión comprende a "todos aquellos que se emplean en el cumplimiento de la prestación prometida del deudor"50. Esta definición amplia de auxiliar es posible aplicarla a toda clase de deudores, inclusive al deudor del deber de ocupación efectiva y adecuada, como es el caso del empleador. Analizando esta categoría desde el punto de vista de la relación de trabajo, es dable sostener que dentro de la actividad de "auxiliares del empleador", además de los otros trabajadores de la empresa, deberían comprenderse todos aquellos sujetos cuya intervención sea promovida por el empleador y que su actuación sea completamente ajena al trabajador, entendiéndose éste como acreedor del deber de ocupación efectiva y adecuada ${ }^{51}$. Es decir, dentro de esta categoría deberían comprenderse tanto los auxiliares directos o ayudantes, quienes se relacionan con el empleador a través de una relación de dependencia y bajo sus instrucciones directas, y por otro lado, también puede ubicarse otro grupo de auxiliares constituido por aquellas personas que trabajan para el empleador en régimen de trabajo transitorio, eventual o de puesta a disposición de trabajadores regulado en los artículos $183-\mathrm{F}$ y siguientes del Código del Trabajo, en cuanto reciben instrucciones directas del empleador ${ }^{52}$.

Además, dentro de esta misma categoría de riesgos, junto con los auxiliares en sentido estricto, también hay que ubicar a aquél grupo de personas constituido por los sustitutos, que son aquéllas personas a las que el empleador entrega en todo o en parte la ejecución de su negocio. Éstos se caracterizan porque desarrollan su actividad en forma autónoma y no simplemente colaborando con aquél, sino en definitiva reemplazándolo ${ }^{53}$. En esta categoría se deberían incluir a los subcontratistas.

En segundo lugar, junto con los auxiliares y los sustitutos, también aparecen como sujetos involucrados en la actividad del empresario los proveedores del mismo: Aquéllos que suministran a su empresa los insumos o materias empleadas en el desarrollo de su actividad, por ejemplo, el productor de verduras que provee a un restorán. Si bien no se puede afirmar que los proveedores colaboran o intervienen en la ejecución del negocio propiamente tal, sí cabe calificar su función como un presupuesto del oportuno y correcto cumplimiento por parte del empresario que recurre a ellos $^{54}$. En efecto, una falta de suministro puede dar lugar al cierre de un determinado negocio, y por ende una infracción por parte del empresario de su deber de ocupación efectiva y adecuada respecto de sus trabajadores. De ahí, entonces que su participación integre el riesgo típico de la empresa.

Lo expresado en los párrafos anteriores permite concluir que la actividad de todos los sujetos mencionados pertenece al riesgo típico de una empresa. La necesidad de intervención de los mismos claramente es una circunstancia conocida por todo empresario, y por lo tanto es consciente, o debe serlo, del riesgo de que un hecho que haga imposible el cumplimiento del deber de

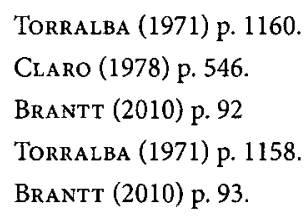


ocupación efectiva pueda originarse en la actuación de alguno de ellos. Por lo mismo, a su vez, el trabajador confía en que su empleador haya tenido en cuenta ese riesgo, que lo ha tomado en consideración al celebrar el contrato y espera por lo tanto que lo controle ${ }^{55}$, evitando que se concrete, y de no ser así, que asuma las consecuencias dañosas del incumplimiento, las que se traducen en la obligación de pagar las indemnizaciones por término de contrato. Por ello, si el riesgo proveniente de la intervención de alguno de estos sujetos en definitiva se concreta, produciéndose un incumplimiento del deber de otorgar el trabajo convenida, y en consecuencia un despido, el empleador no podrá alegar su exención de responsabilidad.

Por lo demás, estas concepciones doctrinarias tienen sustento en el derecho chileno, no obstante la ausencia en el Código Civil de una regla de carácter general que establezca la responsabilidad del deudor por los incumplimientos originados en la actividad de las personas involucradas en la ejecución de sus obligaciones propias. Así, la norma del artículo 1679 del Código Civil, que dispone que en el hecho o culpa del deudor se comprende el hecho o la culpa de las personas por quiénes fuere responsable. En este sentido cabe destacar que dicha responsabilidad se plasma en las siguientes disposiciones del Código Civil: artículos 1925, 1926, 1941, 2000, 2003 regla tercera, 2014, 2015, 2135, 2242 y 2243. Estas disposiciones dispersas en la regulación particular de los contratos recogen la misma idea, permiten sostener esta responsabilidad como una regla general aceptada por el legislador nacional. El problema que plantea el tema es definir a qué se refiere el artículo 1679 con la expresión genérica "personas por las que el deudor es responsable".

Las alternativas serían tres. En primer término, entender comprendidas en esta categoría sólo a las personas aludidas en las normas particulares respectivas, con lo que la responsabilidad del empleador por terceros quedaría reducida a los casos previstos por la ley ${ }^{56}$. La segunda posibilidad sería aplicar la norma del artículo 2320, ubicado en sede de responsabilidad extracontractual $^{57}$. Y, por último, como tercera alternativa, está la de interpretar las diversas normas que admiten dicha responsabilidad como manifestación de una regla general. Esta última es la opinión mayoritaria de la doctrina nacional ${ }^{58}$, y ha sido acogida también por los Tribunales ${ }^{59}$. Ello permite sostener en el derecho chileno, la responsabilidad del deudor en todos los supuestos de intervención de terceras personas en las actividades destinadas a preparar y ejecutar su prestación.

Por último, cabe destacar que entre los autores nacionales, Claro Solar se acerca bastante a las ideas planteadas cuando afirma que "es necesario que el deudor responda de una manera absoluta del derecho de sus auxiliares. Debe soportar el riesgo de la inejecución por la culpa de las personas que se ve obligado a emplear. Este riesgo es para él un pasivo de la empresa que debe tomar en cuenta como otras eventualidades desfavorables ", agregando luego que "no constituye este riesgo un caso fortuito o de fuerza mayor" (Claro, 1978, p. 54).

\section{CONCLUSIONES}

A partir de lo examinado precedentemente, es posible concluir:

La interpretación del concepto y función del caso fortuito ha sido tratada por la doctrina jurídica desde las distintas áreas del derecho. Estudiado este concepto como causal de término de

55 BrantT (2010) p. 105.

56 Coustasse e Iturra (1958) p. 94.

57. Meza (1997) p. 448.

58 Claro (1978) p. 541; Abeliuk (2008) p. 539; Fueyo (1958) p. 276.

59 Montecinos con Hospital Clínico Pontificia Universidad Católica de Chile (2007). 
Juan Luis Castro Jara / Caso fortuito o fuerza mayor como causal de término de la relación laboral. Requisitos del caso fortuito ¿se confunden con la inimputabilidad del empleador?

la relación laboral, los autores especializados han coincidido en construirlo sobre la base de diversos elementos que suponen una construcción más o menos objetivada que no se identifica con la sola ausencia de culpa.

De acuerdo a la doctrina iuslaboralista tradicional, la exigencia del cumplimiento copulativo de los diversos elementos del caso fortuito permite que no se reduzca su análisis sólo a su elemento subjetivo, sin embargo, la finalidad práctica del contrato de trabajo, que establece derechos y obligaciones para ambas partes, $y$ las amplias posibilidades que existen en la actualidad para perseverar en la relación laboral, no obstante los acontecimientos que puedan sobrevenir, muestran la necesidad de replantear la manera en que ha sido entendido el caso fortuito o fuerza mayor como causal de término de la relación laboral, máxime cuando esta causal de término del contrato de trabajo no tiene una regulación especial en la ley, por lo que no difiere de manera sustancial del concepto estudiado desde el derecho común como causal eximente de responsabilidad.

Cabe recordar que la causal de término de contrato de trabajo caso fortuito o fuerza mayor debe necesariamente estudiarse desde la esfera de la responsabilidad contractual, desde que existe un vínculo jurídico entre trabajador y empresario, por lo que cobran especial relevancia las normas establecidas en el Código Civil a este respecto.

En el nuevo escenario en que se desarrolla la relación de trabajo, a fin de determinar la responsabilidad del empleador al invocar la causal de término de contrato establecida en el numeral 6 del artículo 159 en estudio, cobra especial relevancia el análisis de su imputabilidad respecto al hecho provoca el fin de la relación laboral, tal como ocurre en materia civil, por lo que es posible en definitiva reducir al análisis de este requisito, esto es, al elemento subjetivo, la configuración de la causal en estudio.

Así, acreditándose que no existió dolo ni culpa del empleador en el acontecimiento que provoca la imposibilidad de perseverar en la relación laboral, se configuraría la causal de término en estudio. En caso contrario, si se determina que existió culpa en el hecho que se imputa como fortuito, no se configura la causal, y por ende al empleador se le aplica la sanción correlativa que es precisamente la indemnización de perjuicios, que en el proceso laboral se traduce en el pago una indemnización tarifada, cual es las indemnizaciones por término de contrato, recargándose la indemnización por años de servicio en un 50\% de acuerdo a lo dispuesto en el artículo 168 del Código del Trabajo.

Pero no sólo de su propia culpa responde el empleador, sino también de las personas que de él dependen, sin embargo, esta responsabilidad también se analiza desde la forma cómo el empleador, quien es el deudor del deber de protección efectiva y adecuada, ha cumplido con sus obligaciones contractuales, cobrando relevancia también a este respecto el análisis de la debida diligencia en orden a prever el actuar de los auxiliares o sustitutos del empresario, los que sin lugar a dudas participan en la actividad de la empresa, razón por la cual no es posible exonerarse de responsabilidad por parte del empleador para el caso que el hecho que hace imposible perseverar en la relación de trabajo. A contrario sensu, si el acontecimiento que provoca el término de la relación laboral se origina por la actividad de las personas que dependen del empleador, sin embargo, no se debe a dolo o culpa de ellas, se configura igualmente la causal del artículo $159 \mathrm{~N}^{\circ} 6$ del Código del Trabajo, quedando terminado el contrato sin derecho al pago de las indemnizaciones por término de contrato para el trabajador.

En definitiva, la causal de término de contrato en estudio no difiere de la causal de exoneración de responsabilidad regulada en el derecho común. Refuerza esta idea la circunstancia que mientras el empleador es deudor del deber de ocupación efectiva y adecuada, del cual deriva la obligación de otorgar el trabajo convenido, el acreedor de esta obligación es precisamente el tra- 
bajador, por lo que incumpliéndose la obligación señalada, no existiría inconveniente para aplicar las normas del derecho común a esta situación.

En este sentido, para la configuración de la causal de término de contrato establecida en el numeral 6 del artículo 159 del Código del Trabajo, necesariamente el análisis que deberá realizar el juez que se pronuncia sobre la justificación del despido, debe ser desde el aspecto subjetivo del actuar del empleador, respecto al hecho que se reputa como fortuito para poner término a la relación laboral, es decir, forzosamente el análisis de la causal se agota en la inimputabilidad del empleador revisada desde la forma como éste da cumplimiento a sus obligaciones contractuales. En otros términos, para determinar la procedencia de la causal de término caso fortuito o fuerza mayor, es menester realizar un juicio de reproche respecto de la forma cómo el empleador ha dado cumplimiento al contrato de trabajo, siendo los demás requisitos doctrinarios de la causal, meras facetas de la imputabilidad.

Analizar el concepto de caso fortuito o fuerza mayor como causal de término del contrato de trabajo sólo desde su aspecto subjetivo, no implica en caso alguno menoscabo para el trabajador desde que de acuerdo a las normas sobre responsabilidad contractual estudiadas, si el empleador invoca esta causa, precisamente deberá recaer en él el peso de la prueba en orden a acreditar el cumplimiento diligente de sus propias obligaciones contractuales. Por su parte, a través de este análisis del elemento subjetivo respecto del cumplimiento de las obligaciones contractuales del empleador, es posible diferenciar cada situación respecto de cada empleador que la invoca por cuanto mientras para algunos empresarios determinado hecho podría significar la imposibilidad de perseverar en el contrato de trabajo de sus empleados, para otros no.

Trabajo recibido el 8 de julio y aprobado el 29 de julio de 2015

\section{BIBLIOGRAFÍA}

BLAS, Jorge (1990): La estabilidad en el empleo y la terminación del contrato de trabajo, RJ.T, año LXI, $\mathrm{N}^{\circ} 12$, p. 55.

BrantT, María (2010): El caso fortuito y su incidencia en el derecho de la responsabilidad civil contractual: concepto y función del caso fortuito en el código civil chileno. (Santiago, Abeledo Perrot Legal Publishing).

Brantr, María (2009): La exigencia de exterioridad en el caso fortuito: su construcción a partir de la distribución de los riesgos del contrato, Revista de Derecho de la Pontificia Universidad Catolica de Valparaiso, XXXIII.

Cataldo, Hugo y Flores, Eduardo (2012): Breve reflexión en torno al caso fortuito o fuerza mayor en el derecho del trabajo, Revista Actualidad Jurídica, año 13, N 26.

Claro, Luis (1978): Explicaciones de Derecho Civil y Comparado. (Santiago, Editorial Jurídica de Chile)

Coustasse, Alberto e IturRa, Fernando (1958): El caso fortuito ante el Derecho Civil. (Santiago, Editorial Jurídica de Chile).

Diccionario de la Real Academia de la Lengua Española (2015): Disponible en: <http://lema.rae.es/ drae $/$ ?val $=$ caso $>$

FERNÁNDEZ, Javier (2006): Identificación de la fuerza mayor y su distinción del caso fortuito: la operatividad del artículo 30 del Estatuto de los Trabajadores ante la presencia de estos supuestos, Revista Jurídica del Perú, Año LVI, $\mathrm{N}^{\circ} 66$.

FernáNDEZ, Juan José (1993): Expedientes de regulación de empleo (Madrid, Editorial Trotta S.A.)

Fernández, René y Holgado, Leonardo (2010): “Impacto Laboral del terremoto en las regiones afectadas". Disponible en: <http://www.fae.usach.cl/fae1/docs/coyuntura/2010/Informe_de_Coyuntura_Financiera_07.pdfs

FueYo, Fernando (1958): De las Obligaciones, tomo II. (Santiago, Editorial Universo) 
Juan Luis Castro Jara / Caso fortuito o fuerza mayor como causal de término de la relación laboral. Requisitos del caso fortuito ¡se confunden con la inimputabilidad del empleador?

Fueyo, Fernando (2004): Cumplimiento e Incumplimiento de las Obligaciones. (Santiafo, Editorial Jurídica de Chile). Gamonal, Sergio y Guidi, Caterina (2010): Manual del Contrato de Trabajo (Santiago, LexisNexis Abeledo Perrot) GonZÁlez, Osvaldo (1991): La terminación del contrato de trabajo, R.J.T., año LXII Nº 8, p. 59.

Jousserand, Louis (2008): Teoria General de las Obligaciones. (Santiago, Editorial Parlamento Ltda.)

KirSTEN, Maria (2010): Los efectos jurídico-laborales del terremoto del 27 de febrero de 2010- Una mirada desde el Derecho Internacional, Revista Laboral Chilena $\mathrm{N}^{\circ} 189$.

Meza, Ramón (1997): Manual de Derecho Civil: de las obligaciones. (Santiago, Editorial Jurídica de Chile).

Ramos, René (2004): De las Obligaciones. (Santiago, LexisNexis).

Reyes, Alfonso (1997): Imputabilidad. (Santa Fe de Bogotá, Editorial Temis S.A.).

Rodríguez, Pablo (2006): Extinción convencional de las obligaciones. (Santiago, Editorial Jurídica de Chile).

Rodríguez, Victoria (1964): El caso fortuito ante la jurisprudencia chilena. (Santiago, Editorial Universitaria).

Rojas, Irene (2004): Manual de Derecho del Trabajo. (Santiago, LexisNexis).

Soro, Francisco (1965): El caso fortuito y la fuerza mayor: los riesgos en la contratación. (España, Ediciones Nauta).

Soтo, Mario (2010). ¿Un terremoto constituye un "caso fortuito o fuerza mayor"?, Revista Laboral Chilena $\mathrm{N}^{\circ} 185$.

STitchкin, Sergio (1964): La responsabilidad, el caso fortuito y la culpa ante la jurisprudencia. (Concepción)

Thayer, William y NovoA, Patricio (1998): Manual de Derecho Individual de Trabajo. Tomo II. (Santiago, Editorial Jurídica de Chile).

Torralba, Orencio (1971): La responsabilidad por los auxiliares en el cumplimiento de las obligaciones, Anuario Derecho Civil $\mathrm{N}^{\circ} 24,4$.

Troncoso, Hernán (2006): De las Obligaciones. (Santiago, LexisNexis).

VARAs, Karla (2010): Caso fortuito o fuerza mayor: requisitos para constituir una exoneración de la responsabilidad del empleador, Revista Laboral Chilena $\mathrm{N}^{\circ} 189$.

VArAs, Karla (2010): ¿Qué pasa con los derechos de los trabajadores tras el terremoto?, Revista Laboral Chilena $\mathrm{N}^{\circ} 186$.

Vivanco, M. (1994): El despido laboral. (Santiago, Editorial Jurídica de Chile).

\section{NORMAS CITADAS}

Decreto Ley $\mathrm{N}^{\circ} 3.607$, de 8 enero de 1981, establece nuevas normas sobre funcionamiento de vigilantes privados.

Decreto Supremo 93, de 21 de octubre de 1985, aprueba reglamento modificatorio Decreto Ley $\mathrm{N}^{\circ} 3.607$.

\section{JURISPRUDENCIA JUDICIAL}

Alvarado con Industrial Centec S.A. (2008): Corte de Apelaciones de Temuco, 30 de Diciembre de 2008 (recurso de apelación), disponible en www.pjud.cl (base jurisprudencial), Rol N ${ }^{\circ}$ 1674-2008.

Alvarado y otros con Industrial Centec S.A. (2009): Corte Suprema, 8 de Abril de 2009 (recurso de casación en el fondo), disponible en www.pjud.cl (base jurisprudencial), Rol $\mathrm{N}^{\circ}$ 1021-2009.

Cea con Medina (2012): Corte Suprema, 11 de Abril de 2012 (recurso de unificación de jurisprudencia). disponible en www.pjud.cl (base jurisprudencial), $\mathrm{Rol} \mathrm{N}^{\circ}$ 6008-2011.

Cofré con Heller (2006): Corte Suprema, 30 de Octubre de 2006 (recurso de casación en el fondo), disponible en www. pjud.cl (base jurisprudencial), Rol $N^{\circ} 847-2005$. 
Juan Luis Castro Jara / Caso fortuito o fuerza mayor como causal de término de la relación laboral. Requisitos del caso fortuito ;se confunden con la inimputabilidad del empleador?

González con Compagnon (2005): Corte Suprema, 21 de Julio de 2005 (recurso de casación en el fondo), disponible en www.pjud.cl (base jurisprudencial), Rol N 2323-2004 y en http://jurischile.blogspot.com/2005/07/despidoinjustificado-docente.html

Herrera con Mondiglio (2006): Corte de Apelaciones de Santiago, 28 de Marzo de 2006 (recurso de apelación), disponible en www.pjud.cl (base jurisprudencial), Rol $\mathrm{N}^{\circ}$ 4456-2005, y en http://jurischile.blogspot. com/2006/10/incendio-parcial-del-lugar-de-trabajo.html

Herrera con Sociedad Contractual Minera Tambillos (2009): Juzgado de Letras del Trabajo de La Serena, 27 de Noviembre de 2009 (acción de despido injustificado), disponible en www.pjud.cl (base jurisprudencial), causa RIT O-253-2009, y en http://jurischile.blogspot.com/2010/09/despido-injustificado-al-aducir-despido.html

Inmobiliaria Italia Ltda. con Jar Ingeniería y Servicios (2006): Corte de Apelaciones de La Serena, 12 de diciembre de 2006 (recurso de apelación), disponible en www.pjud.cl (base jurisprudencial), Rol Nㅜ 5703-2000.

Inostroza con Inzunza (2008): Corte de Apelaciones de Concepción, 11 de Noviembre de 2008 (recurso de apelación), disponible en www.pjud.cl (base jurisprudencial), Rol $N^{\circ}$ 186-2008, y en http://jurischile.blogspot. com/2008/11/caso-fortuito-y-acto-de-autoridad.html

Luarte con Sociedad Comercial e Industrial Ramirez Diaz Hnos. (2006): Corte de Apelaciones de Concepción, 1 de septiembre de 2006 (recurso de apelación), disponible en www.pjud.cl (base jurisprudencial), Rol N ${ }^{\circ} 4566-$ 2005, y en http://jurischile.blogspot.com/2006/11/trmino-de-relacin-laboral-por.html

Mazzo con Buses Gran Santiago S.A. (2011): Segundo Juzgado de Letras del Trabajo de Santiago (acción de despido injustificado), disponible en www.pjud.cl (base jurisprudencial), causa RIT O-2998-2010, y en http:// jurischile.blogspot.com/2012/06/indemnizacion-por-despido.html.

Montecinos con Hospital Clínico Pontificia Universidad Católica de Chile (2007): Corte Suprema, 24 de septiembre de 2007 (recurso de casación en la forma y en el fondo), disponible en www.pjud.cl (base jurisprudencial), Rol $\mathrm{N}^{\circ} 4103-2005$.

Morales con Harbison-Walker Refractories S.A. (2009): Corte Suprema, 2 de junio de 2009 (recurso de casación en el fondo), disponible en www.pjud.cl (base jurisprudencial), Rol No 1673-2009, y en http://jurischile.blogspot. com/2009/07/ausencia-al-trabajo-originadas-por.html.

Olate con Empol Chile Say Empol S.A. (2006): Corte de Apelaciones de Santiago, 27 de noviembre de 2006 (recurso de apelación), disponible en www.pjud.cl (base jurisprudencial, Rol N ${ }^{\circ} 1270-2006$, y en http://jurischile. blogspot.com/2007/06/despido-injustificado-quiebra-de-la.html

Pozo con Transportes Servidiario S.A. (2007): Corte de Apelaciones de Santiago, 27 de Septiembre de 2007 (recurso de apelación), disponible en www.pjud.cl (base jurisprudencial), Rol N ${ }^{\circ}$ 5703-2000.

Ramirez con Empresa de Transportes Compañia de Seguridad Ltda. (2011): Corre Suprema, 4 de Octubre de 2011 (recurso de casación en el fondo), disponible en www.pjud.cl (base jurisprudencial, Rol No 2037-2011.

Silva con Fluor Chile S.A. (2010): Corte de Apelaciones de Santiago, 5 de agosto de 2010 (recurso de apelación), disponible en www.pjud.cl (base jurisprudencial), Rol $\mathrm{N}^{\circ}$ 546-2010 y en http://jurischile.blogspot. $\mathrm{com} / 2010 / 09 /$ ausencia-de-trabajador-por-encontrarse.html

Smart con Inmobiliaria e Inversiones Pangal S.A. (2008): Corte Suprema, 23 de Octubre de 2008 (recurso de casación en el fondo), disponible en http://jurischile.blogspot.com/2009/01/caso-fortuito-o-fuerza-mayorcomponentes. html

Sociedad Aussicht Chile Ltda. con Municipalidad San Francisco de Mostazal (2006): Corte Suprema, 24 de agosto de 2006 (recurso de casación en la forma), disponible en www.pjud.cl (base jurisprudencial), Rol No 1913-2004.

Suazo con CODELCO Chile, División CODELCO Norte (2011): Corte Suprema, 4 de abril de 2011 (recurso de casación en la forma), disponible en www.pjud.cl (base jurisprudencial), Rol $N^{\circ}$ 7270-2009.

\section{JURISPRUDENCIA ADMINISTRATIVA}

Dirección del Trabajo. Ord. Nº 1412/021, de 19 de marzo de 2010. 